\title{
Niños populares y escuela popular: un estudio sobre las dificultades del proceso de escolarización en Chile (1840-1860)
}

\author{
Emilio Ramírez Bizama ${ }^{1}$
}

Universidad de Chile, Santiago de Chile. Email: Emilioramirez@live

Resumen: ${ }^{2}$ El presente artículo, primero, reflexiona sobre el ideal de nación en construcción a través de las escuelas primarias. Luego se estudia el rol de los visitadores de escuela, y después, analizando los informes que éstos redactaron, se exponen las dificultades -que dividimos en sociales y académicas- del proceso de escolarización, considerando permanentemente las prácticas y actitudes de los niños populares.

Palabras clave: niños populares, escuela primaria, escolarización, visitadores de escuela.

\section{Children of popular sectors and school of popular sector: a study about difficulties of the process of schooling in Chile (1840-1860)}

\begin{abstract}
This article, first, thinks about the ideal of a nation in construction by studying its primary schools. Second, the role of school's visitors is studied, and later, by analyzing the reports that these wrote, the difficulties of the process of education are exposed -which we divide in social and academic-, considering permanently the practices and attitudes of the children of the popular sectors. visitors.

Key words: children of popular sectors, primary school, schooling, school's

\section{Crianças populares e escola popular: um estudo das dificuldades do processo de escolarização no Chile (1840- 1860)}

Resumo: Este artigo reflete em primeiro lugar, sobre o ideal de nação em construção através das escolas primárias. Em seguida estuda o papel dos visitantes escolares e depois analisa os relatórios que eles escreveram, expondo as dificuldades -que se dividem em sociais e acadêmicas- do processo de ensino, considerando permanentemente as práticas e atitudes das crianças populares.

Palavras-chave: crianças populares, escola primária, escolarização, visitadores de escola. 


\section{Introducción (la escuela y la nación)}

Otra de las causas que opone una tenaz resistencia al desarrollo de la instrucción primaria, es la poca concurrencia en las escuelas de los campos.

Informe visitador de escuelas de la provincia de Talca, Julio 1860.

La situación de Concepción es como la de las demás provincias. Lo que falta no son escuelas, sino alumnos; y aun podría decirse que lo que falta no son niños en estado de recibir la instrucción primaria en sus rudimen-

tos, sino estímulo en el pueblo para aprovechar los beneficios que les ofrece el Estado.

“Escuelas en el sur”, El Monitor de Escuelas Primarias, mayo 1856.

Un día llegará sin embargo, es de esperarlo en honor de los pueblos españoles, en que la educación primaria que se dé a los niños, sea asunto digno de la conversación y de la solicitud del hogar doméstico.

El Monitor de Escuelas Primarias, agosto 1852.

Construir una nación implicó alterar la identidad de los niños populares. Las élites se propusieron la confección de una nación homogénea, es decir, una nación en la que sus integrantes habitaran una misma época: en una era moderna, civilizada y ordenada y sin cuestionar la jerarquía social establecida. Sin embargo, los niños populares no cumplían con el perfil de nación en construcción, muy por el contrario, eran vistos como "bárbaros”, "incultos” e "ignorantes”, y desconocían la jerarquía social imperante al habitar en una cotidianeidad marginal. Por esto es que se creó desde el Estado un sistema educativo -y un proceso de escolarización- como un medio para transformar las costumbres de los niños populares, pero perpetuando su subalternidad; disciplinándolos e instruyéndolos en normas antes desconocidas tales como el tiempo de asistencia a la escuela, el orden en el aula, la obediencia y conocimientos elementales que permitiesen alcanzar el ideal de nación que las élites esperaban consolidar, esto, bajo el proyecto de "educación popular" impartido por el Estado chileno, proyecto que tuvo sus primeros pasos entre 1840 y $1860 .^{3}$

Hasta la década 1840, indicaba Domingo Faustino Sarmiento, “había educación para las clases gobernantes, para el sacerdocio, para la aristocracia; pero el pueblo, la plebe [sic] no formaba, propiamente hablando, parte activa de las naciones” (Sarmiento 1849:10). En otras palabras, hasta 1840 la nación habitaba tiempos heterogéneos, desiguales “desde arriba” y “desde abajo”. La plebe, como señalaba Sarmiento, se encontraba diseminada, desintegrada. Por ello es que la tarea de las élites consistía en integrar a estos sectores, pero no para entregar igualdad de oportunidades o movilidad social, sino para que éstos comprendieran el rol que debían jugar en la sociedad. 
La concurrencia a la escuela cumpliría un rol fundamental: agregaría en los niños "una autoridad más a la paterna, [... ] lo que empieza ya a formar el espíritu a la idea de una autoridad fuera del recinto de la familia [...] para prepararlos a las obligaciones y deberes de la vida de adultos” (Ibíd: 24). De este modo se imponía en los niños populares un tiempo antes desconocido, una temporalidad “"normal”, que es la de la dominación. Esta impone sus ritmos, sus escansiones del tiempo y plazos. Fija el tiempo de trabajo [o de asistencia a la escuela] y de su ausencia [...]" (Ranciére 2010:9). Este tiempo de la dominación "separa entre quienes tienen tiempo y quienes no lo tienen; decide qué es lo actual y qué es ya pasado. Se empeña en homogeneizar todos los tiempos en un solo proceso y bajo una misma dominación global” (Ibíd.). Dicho de otro modo, se impuso un tiempo que intentó alterar las costumbres de los niños populares para que adquirieran nociones preestablecidas "desde arriba”. Se impuso un tiempo, llamémosle como Rancière, de dominación, que homogenizó -a partir de un Estado centralizador que utilizó la escuela como medio para ese fin- al niño popular con los intereses de las élites, impidiéndole la oportunidad de ser un productor de su propia realidad y obligándolo a reproducir los dictámenes del Estado.

Podemos graficar la idea anterior observando las propuestas de, por ejemplo, los hermanos Amunátegui. Estos se preguntaban: “¿Los niños deberán concurrir a la escuela durante todo el curso del año, excepto unas cortas vacaciones, o solo durante ciertos períodos determinados?” (Amunátegui 1856: 119). La respuesta era relativa, pues aseguraban que:

"Habrá niños que deberán concurrir a la escuela durante todo el año. Esos serán por lo general los niños de las ciudades, los hijos de la gente acomodada. Habrá otros que solo podrán concurrir en ciertos períodos determinados. Esos serán los niños de los campos, los hijos de los pobres. En las familias de las últimas clases los niños auxilian a sus padres en el trabajo, les ayudan a ganar el sustento. No sería justo por consiguiente hacer que esos niños se dedicaran exclusivamente a la escuela.” (Ibíd.)

A pesar de la observación descrita, los hermanos Amunátegui terminaban advirtiendo que de materializarse la última declaración -la asistencia exclusiva a la escuela de los niños populares dejando a un lado su trabajolas consecuencias serían "resistencias muy violentas” (Ibíd.). El ejemplo es claro. "Desde arriba" se establecían las medidas; se estipulaba quiénes debían pasar más tiempo en la escuela y quiénes no. Cabe aclarar, no obstante, que en ningún caso se desconoció la realidad “de abajo”. Se entendía que ahí, "abajo", los niños populares durante el año trabajaban", que en su cotidianeidad aprendían las tareas para subsistir, pero a pesar de ello, bajo esta nueva temporalidad, los niños populares debían asistir a la escuela, aunque fuera durante unas escasas horas, las suficientes para ir "aprendiendo" los códigos y lenguajes que les permitirían comprender los designios de quienes deseaban inscribir al país en la modernización occidental. 
Pero aquí surge una pregunta, pues si los niños populares en su cotidianeidad aprendían la subsistencia, entonces ¿por qué debían ir a la escuela? Si no habría movilidad social, insistimos, ¿para qué debían asistir a la escuela? La respuesta, es que en esta nueva era -civilizada y modernalos niños populares, dejando atrás la “ignorancia”, debían aprehender conductas desconocidas y adquirir comportamientos disciplinados. En esta nueva era civilizada las escuelas debían intervenir "diariamente sobre el espíritu de los niños, educando su gusto, su físico y sus inclinaciones [...y] habituar sus sentidos a vivir en medio de estos elementos indispensables de la vida civilizada” (Sarmiento 1849: 195). La escuela debía instruir al niño popular en la disciplina para que creciera apercibido de sus nuevas obligaciones. Y es que en la escuela se aprendería, como una lección de vida, el orden, la sumisión, el premio y el castigo:

"La asistencia sola a la escuela donde se enseñan la lectura y escritura, y la disciplina que se observa en ella, propenden activamente a la educación del corazón de los alumnos. Los niños, generalmente hablando, contraen en la escuela hábitos de orden, de sumisión, de trabajo continuado e incesante, que más tarde no pueden olvidar. En el taller, o en cualquier otra parte, desplegarán las mismas virtudes que en la escuela. El alumno acostumbrado a llenar sus deberes con exactitud, a desempeñar una tarea cada día, a sufrir un castigo si no cumple con ella, a recibir un premio si se porta con la constancia y aplicación debidas, será con toda probabilidad un individuo honrado, que no faltará nunca a su palabra, que ejecutará sus obras con método, que no se dejará arrastrar por la pereza, que se esforzará por imprimir el sello de la perfección a cuanto salga de sus manos” (Amunátegui 1856: 20-21).

De este modo, la escuela primaria popular se construyó como un medio para alcanzar un fin. Como una máquina, o como dijera Sarmiento, como una "fábrica, [es decir], una usina de instrucción” 5 , donde se enseñaran las normas de esta nueva época. Cabe reiterar: la educación primaria era un medio para un fin, un instrumento para alcanzar la civilización, pero no era la civilización. En palabras de los hermanos Amunátegui, la "instrucción primaria es uno de los principios que conducen a la civilización, pero no es la civilización.” (Amunátegui 1856:83). La escuela era el medio para que Chile dejara de ser un "sordo mudo de la civilización” y pasara a ser un "Chile floreciente en el interior, poderoso en la América, respetado en la Europa, notable en el orbe de la tierra” (Ibíd: 3). ${ }^{6}$

Mediante esta “fábrica” se debía integrar a los sectores populares, pero de manera desigual. Dicho de otro modo, hubo que consolidar una “desigualdad entre iguales”; de ahí el diseño de un sistema educativo clasista, para dos tipos de clase: la educación secundaria para los niños de élite, y la instrucción primaria para los niños populares, "porque la instrucción [se pensaba] debe adaptarse a las diferentes condiciones, y habilitar al hombre para vivir en el puesto que le ha cabido” (Montt, MMJCIP, 1842: $25)^{7}$. Las élites estipularon que "no todos los hombres han de tener igual 
educación, aunque es preciso que todos tengan alguna, porque cada uno tiene distinto modo de contribuir a la felicidad común” (El Araucano, 29 de Julio de 1836$)^{8}$. Bajo esta óptica Antonio Varas, ministro del ramo hacia 1845, determinaba que:

“La diversa posición social exige también diversa cultura intelectual. Para la clase que vive del trabajo de sus manos, y que desde muy temprano se ve precisada a ganar por sí la subsistencia, la instrucción primaria es todo lo que puede adquirir. Para la clase que con más desahogo puede y debe dedicar más tiempo al cultivo del entendimiento, es preciso proporcionar más extensos medios de instrucción que las escuelas primarias, no sólo por consideraciones al bien del individuo, sino principalmente en favor del bien social. Esta clase es llamada a ejercer una influencia efectiva en el bien del país por las ventajas que la da su posición y porque de ellas deben sacarse los que han de ejercer funciones sociales de alguna importancia” (Varas, MMJCIP, 1845: 29).

Entregar dos tipos de educación para dos tipos de clase era para las élites una cuestión natural. El paradigma, la cosmovisión de las élites, era que un sector -ellos- gozaba el privilegio, pero también la responsabilidad, de gobernar; y que a otro sector -los sectores populares- le correspondía la sumisión. La escuela primaria popular entonces solo materializaría concepciones previas, reproduciría las desigualdades existentes. La relevancia de la escuela, por consiguiente, no radicaba en la reproducción de las desigualdades, pues ya existían, sino en que los niños aprendieran a respetar esas desigualdades. De este modo, los sectores populares debían contentarse sólo con lo ofrecido por las élites, porque:

"Esos individuos [los sectores populares] son la polilla de la sociedad; entre ellos recluta el despotismo sus instrumentos y la demagogia sus atizadores de revueltas. Para conciliar la satisfacción de las dos necesidades señaladas, esto es, la de una instrucción general y barata para el común de los niños, y la de una instrucción más elevada para aquella porción que por su riqueza o por su talento puede dedicar más tiempo al estudio, hay un arbitrio expedito que todo lo allana: la creación de dos especies de escuelas, las unas elementales, donde se enseñarán los rudimentos estrictamente indispensables, y las otras superiores, donde se enseñará, no solo que es esencial, sino también algo de lo que es útil” (Ibíd.).

Este último relato ilustra fielmente el pensamiento de las élites de la época; la jerarquización social que se cimentaba en el ideal de nación transmitido mediante las escuelas primarias, la división de clases y la reproducción de un sistema que invitaba al niño popular a asistir a la escuela primaria popular para luego, paradójicamente, continuar subsistiendo en su cotidianeidad. 


\section{Los visitadores y los niños}

Exponíamos anteriormente el ideal de nación que se esperaba construir mediante las escuelas primarias, y cómo éste reinscribía una desigualdad considerada natural y coherente. Sin embargo, ¿qué ocurrió en la práctica? ¿Cómo reaccionaron los niños populares frente a esta política?9 ${ }^{9}$ Para saberlo es preciso primero comprender a los visitadores de escuela, ya que "nadie mejor que los visitadores puede conocer los adelantos que hace este ramo, ni nadie mejor que ellos puede saber el motivo, por oculto que se halle, que impida el fomento de la enseñanza” (MEP 1859, tomo VII, $\left.n^{\circ} 6: 179\right){ }^{10}$

Podríamos definir a los visitadores de escuela como funcionarios estatales “en terreno”, como un brazo del todavía emergente Estado. Ellos eran quienes visitaban las escuelas de las provincias y departamentos con el objetivo de homogenizar el sistema educativo e integrar a los sectores populares. Distinguimos dos funciones en esta figura: por un lado, se identifica un rol administrativo o académico, empeñado en "uniformar los métodos y contenidos [de enseñanza], normar, ordenar el tiempo y espacio en la escuela y capacitar al profesor” (Egaña 2000: 231). Y paralelamente evidenciamos en éstos un rol, llamémosle, social o conciliador, intercediendo por el Estado en las comunidades locales. Cabe señalar, empero, que no siempre contaron con esa doble función, sino que su rol fue susceptible de modificaciones según la reacción de los sectores populares. Este dato es de suma relevancia; en primera instancia (desde 1847 hasta 1860), los visitadores de escuela sostuvieron las funciones administrativas y sociales del proceso de escolarización, no obstante, al percibir desde el Estado que los sectores populares, en particular los niños populares, no se adaptaban al nuevo modelo educacional-nacional sino que dificultaban su desarrollo, (a partir de 1860) aumentó la inspección, quedando obsoleto el rol conciliador de éstos y conservando únicamente su carácter administrativo.

El cargo de visitador era el último grado que podía alcanzar un preceptor ${ }^{11}$. Para alcanzar el cargo primero debía ser disciplinado él mismo, y luego reproducir el disciplinamiento. Desde el Estado entonces se disciplinó al disciplinador. No debe pensarse que el proceso fue sencillo, véase, por ejemplo, el caso del primer preceptor nombrado visitador de escuelas en 1847, el caso del "celoso joven Bustos que tantas pruebas había dado de una vocación decidida hacia la carrera del preceptorado, y de quien tan útiles servicios se aguardaban en este ramo [pero que, finalmente] sucumbió a las fatigas que le demandó su visita en la provincia de Concepción" (Sanfuentes, MMJCIP, 1849: 20-21).

Poco tiempo después, luego de la fracasada experiencia del "joven Bustos”, se nombró un sucesor, y poco a poco aumentó el número de visitadores de escuelas pues, así como el panóptico de Foucault, el Gobierno necesitaba vigilar todos los puntos del Estado y corregir en las comunidades en general, y en las escuelas y niños populares en particular, el 
incumplimiento de las nuevas normas instauradas de la nación en construcción. Con todo, en el período aquí en cuestión el número de visitadores siempre fue insuficiente para abarcar las trece provincias de la época; hacia 1853 solo había 3 visitadores, en 1854 la cifra se duplicaba a 6, y en 1855 los que ocupaban el cargo eran 8. Recién en 1860, con el dictamen de la Ley de Instrucción Primaria, se pronunciaría formalmente la asignación de un visitador por cada provincia.

En 1854, cuando se duplicó la cifra de visitadores (de 3 a 6), se creó además un decreto titulado "Atribuciones y deberes de los visitadores de escuela”, en el que se dictaban los derechos y obligaciones de estos funcionarios. En este decreto podemos identificar las funciones que mencionábamos líneas más arriba; el carácter administrativo y social de estos inspectores. El decreto contaba con cinco artículos, mas baste citar sólo algunos puntos para ilustrar su intención:

“Art. $1^{\circ}$ Los visitadores de escuelas primarias deberán:

$1^{\circ}$ Ejercer una inspección constante sobre las escuelas de primeras letras, públicas y particulares, comprendidas en el distrito en que funcionan, examinando en cada una de ellas su orden interior, método de enseñanza, textos adoptados en ellas, libros de lectura, aprovechamiento y moralidad de los alumnos, local y útiles del establecimiento, inversión de los fondos que le pertenezcan, conducta y aptitudes del preceptor, y si éste recibe puntualmente las publicaciones que le están destinadas, y envía con exactitud los datos que se le piden.

$2^{\circ}$ Dar disposiciones convenientes para remediar los defectos que observare en cualquiera de los ramos susodichos; acudiendo a la autoridad gubernativa o a la libertad de los vecinos, según los casos, para que se provea a las necesidades que notares.

$5^{\circ}$ Informar a las autoridades sobre cualquier asunto de su incumbencia en que fuesen solicitados por ella, y desempeñar las demás comisiones que se les confíe en el ramo de instrucción primaria, dentro del territorio en que funcionen.

Art. $2^{\circ}$ Además de las funciones que les señala el artículo anterior, incumbe a los visitadores de escuelas para llenar el fin de su institución:

$1^{\circ}$ Excitar el celo de los padres de familia y vecinos de cada lugar a favor de la instrucción primaria, inclinándose a cooperar al establecimiento de las escuelas que necesiten en sus localidades y a la mejora de las que posean. El visitador deberá este efecto, con previa anuencia de las autoridades locales, correr suscripciones entre los vecinos a favor de las escuelas, o reunirlos para hacerles presentes las ventajas de fomentar la educación popular en sus localidades, y lo fácil que les es hacer en este ramo todo el bien apetecible, contribuyendo cada uno con una erogación ligera y proporcionada a sus recursos para conseguirlo"( Boletín de las Leyes y Decretos del Gobierno, Libro XXII, n³, 1 de marzo de 1854: 152). 


\section{Las dificultades sociales}

Los puntos expuestos anteriormente evidencian la doble función de los visitadores de escuela: administrativa y social. En la práctica cumplieron su labor tal como se les ordenó, sin embargo, pese al esmero por ordenar la enseñanza y la fervorosa prédica esparcida en las comunidades, la asistencia a la escuela y la adquisición de un comportamiento disciplinado dentro de ellas tardó varios años en consolidarse ${ }^{12}$. En 1854, por ejemplo, un visitador de escuelas expresaba lo siguiente: "Muy Señor mío: [...] He visto a los vecinos e invitándolos a que pongan a sus hijos en la escuela, me contestan que no los mandan porque van a ella a perder el tiempo" ("Correspondencia”, MEP, Tomo II, $n^{\circ}$ 1, Valdivia, junio 1854: 290). Otro visitador, también alicaído como el testimonio recién expuesto, manifestaba que "a pesar del trabajo asiduo que me tomé por hacer comprender a los vecinos la importancia que reporta la instrucción primaria, no he conseguido el fruto que deseaba [...]” (MEP, Tomo II, n 7, febrero 1854: 197). Y así podríamos seguir enumerando casos, como el de Ñuble, donde:

"El intendente, los Gobernadores, y las demás autoridades han hecho cuanto está a sus alcances para generalizar la educación. Escuelas nuevas se han abierto en todos los centros de poblaciones. Pero estas medidas han sido impotentes para vencer la resistencia que oponen la ignorancia y el espíritu empecinado que ella engendra. La inasistencia continúa, el Estado pierde inútilmente crecidas sumas de dinero y la civilización ve retardados los frutos que debiera recoger! Qué hacer pues? Hasta cuándo esperar” ("Informe de la provincia de Ñuble”, MEP, Tomo V, nº 7, abril 1857: 196).

La escasa fecundidad de las prédicas de los visitadores -llegando incluso al cierre de escuelas por "no tener alumnos que la frecuentasen" ("Instrucción Primaria, MEP, Tomo III, n5, diciembre 1854: 145) - fue atribuida a la "ignorancia” y pobreza de las familias (Rengifo 2012:125). Permanentemente se culpó:

"La negligencia, el descuido, la insensibilidad y la inconsideración de los padres de familia por la educación de sus hijos, que no reservándoles uno o dos años para dedicarlos a la enseñanza, los emplean en quehaceres las más veces insignificantes [el trabajo: siembras y cosechas] dejando para más tarde su enseñanza, para cuando el niño no pueda aprender"' "Informe de las escuelas de la Provincia de Aconcagua”, MEP, Tomo II, nº 6, enero 1854: 163-164).

Podría pensarse que los niños no asistían a las escuelas sólo porque sus padres no los enviaban, y desconocer la conciencia de éstos en tal actitud. No obstante, que el niño popular prefiriera trabajar antes que asistir a la escuela, además de ser una opción del padre, también fue una opción y actitud propia de él, porque como dictaminaba un visitador:

“Si el niño trabajó en una ocasión, él y sus padres quieren ya que 
trabaje siempre. Si dejó la escuela por un deber de necesidad, por la urgencia de prestar un servicio imprescindible, él mismo y sus padres, desconociendo la conveniencia de la educación, la dejan a un lado para no volver jamás a ella.

El padre contando con tener un nuevo auxiliar para sus faenas y un nuevo jornal con que ayudar a las necesidades de la familia, se olvida de la escuela en que el hijo aprendió lo poco que sabe. El niño que ha recibido unas cuantas monedas en pago de su trabajo, que se ha creído hombre al asociarse con los demás hombres, presume haber completado su educación, y, no excitado por ningún estímulo noble, teniéndolos al contrario poderosos a favor de sus inclinaciones, abandona para siempre la escuela, y su porvenir es el del peón [sic] ignorante y disipado.” (“Estado de la educación popular en el Ñuble”, MEP, Tomo IV, nº 7, abril 1856: 194).

Antes que adquirir nuevas obligaciones en la escuela, el niño popular ya tenía las propias. Antes que adaptarse a cumplir horarios escolares para aprender lecto-escritura, aritmética básica y moral cristiana, el niño popular tenía sus tiempos de trabajo determinados, sembrando y cosechando en distintas épocas del año. Esto interrumpía el proyecto educacional-nacional, porque en épocas de cosecha no era extraño que una escuela con más de ochenta alumnos quedara con diez o doce, o incluso, como es el caso de Antuco, con ninguno ("Informe del Visitador de Escuelas de los Ángeles D. Manuel Valenzuela”, MEP, Tomo III, n9, junio 1855: 271). Por ello es que "la inasistencia de alumnos a las escuelas rurales [se consideró] un mal necesario durante cierta época del año para la generalidad de las familias pobres" ("Estado de la educación popular en el Nuble”, MEP, Tomo IV, $n^{\circ} 7$, abril 1856: 194). La alta inasistencia, o la asistencia intermitente de los niños populares a las escuelas, fue la norma en el período aquí estudiado, resignando a los visitadores a describir en sus informes que: "la inasistencia es el más poderoso obstáculo que se opone al progreso de la instrucción primaria” ("Informe que presenta el visitador de las provincia del Ñuble, al señor Ministro de Instrucción Pública”, MEP, Tomo IV, n7, abril 1856: 205); descripción que respondía a la observación de casos de niños que asistían a la escuela solo una semana a cambio de tres o cuatro de inasistencias (Ibíd.), limitando a los niños a un aprendizaje incompleto de las conductas enseñadas, y peor aún para las autoridades, que éstos olvidaran lo aprendido en los días, semanas o meses de inasistencia a la escuela a causa del trabajo. "Llega el invierno [decía el visitador] y vuelve el niño a la escuela tan rústico como lo era antes. De este modo transcurre el tiempo y el alumno pasa así cuatro o seis años; se sale al fin después de haber sacrificado a su preceptor y sacrificándose él, casi tan ignorante como había entrado [...]” (Ibíd.). Como evidencia el relato recién expuesto, muchos niños mantuvieron los mismos conocimientos y hábitos a pesar de asistir a la escuela cuatro o seis años, esto, ya que antes que aprender conocimientos académicos los niños conservaron los propios, los aprendidos fuera de las aulas, en su cotidianeidad, porque "las masas no aceptan por lo general sino aquello que está a su alcance. La razón abstracta no vale nada para ellas, ni la más brillante teoría puede ofrecerles atractivo si no se 
les presenta encarnada en una fórmula perceptible, movible, palpable” ("Escuelas del sur”, MEP, Tomo II, n¹0, mayo 1854: 249); cosa que -está a la vista- la escuela no entregaba:

“ ¿Se necesita de la cartilla para saber domar un potro, para bornear el lazo, para buscar buenos pastos en que engordar los animales? ¿Es preciso por ventura, saber hacer garabatos, para vestir un chiripá y un poncho de bayeta, para tender una res, para hacer una buena cosecha en un pedazo de terreno que el patrón ofrece, y que si no lo ofreciera, se encontraría en cualquiera parte, en la cumbre de una montaña, o sobre las orillas de una inmensa laguna?

He ahí las reflexiones que la gran masa de los habitantes de las aldeas y de los campos debe hacerse con respecto a la instrucción primaria. Reflexiones desconsoladoras, pero lógicas consecuencias de la situación del grado de cultura de esas inteligencias encapotadoras bajo las costumbres rudas y groseras de una vida salvaje [...]” (“Escuelas del sur”, MEP, Tomo II, n¹0, mayo 1854: 250).

Es preciso indicar que el asiduo trabajo para la subsistencia, sumado a la cotidianeidad y experiencias extra-escolares, hizo a los niños populares acreedores de su propia realidad, de su propia identidad, es decir, constructores de su propia historia; historia pocas veces contada, ciertamente. La inasistencia a las escuelas efectivamente provocó la ignorancia en saberes académicos, pero no desconozcamos que, al mismo tiempo, hizo a los niños populares acreedores de otros saberes, distintos, más útiles y valiosos para ellos mismos.

“El ignorante no tiene memoria más larga de la que comprende la miserable vida de un individuo, ni horizonte mucho más del que abraza el campanario de su aldea, ni relaciones más extensas que con sus semejantes, de las que se refieren a la familia o a la vecindad" ("Correspondencia" (Limache), MEP, Tomo IV, n6, marzo 1856: 222). Esta peyorativa acusación frecuentaba los informes de los visitadores, pero haciendo el ejercicio de leer "al reverso" 13 , viendo más allá de lo explícito, entendemos que aquella "ignorancia” que se acusaba, esa corta memoria inherente a una "vida miserable” limitada al contacto familiar y vecinal, no era sino otro tipo de saber, una construcción propia de la realidad. Esta interpretación no solo es historiográfica, sino que además se sustenta bajo criterios de sicología evolutiva. Sin ánimos de desviar esta investigación sino que ayudándonos de otras disciplinas para comprender la realidad del niño popular, tomamos las palabras de Juan Delval, reconocido investigador por sus aportes al respecto, quien determina que:

“Durante su período de desarrollo el niño va formando un representación de los distintos aspectos de la sociedad en la que vive y, aunque esa representación está socialmente determinada, no es el producto de la influencia de los adultos sino el resultado de una actividad constructiva a partir de elementos fragmentarios que recibe y selecciona, de tal manera que el niño realiza una tarea personal 
que no se parece en nada a una asimilación pasiva” (Delval 1989:245).

Podemos ejemplificar esta idea con una correspondencia llegada al redactor del Monitor de las Escuelas Primarias desde Santa Juana, departamento de Lautaro, en la provincia de Arauco, la cual ilustra fielmente lo que intentamos develar tomando el caso de un "niño de la frontera"14. En esta carta escrita por un preceptor conocedor de la realidad de la zona en cuestión se narraba el crecimiento de un niño desde la edad de seis años; pequeño, pero "grandecito y muy esforzado para su edad” ("Correspondencia”, MEP, Tomo IV, n¹, octubre 1855: 21). De antemano el relato presentado advertía que describiría la realidad “del hijo del vaquero, del hijo del proletario de la frontera, y no del hijo del habitante que tiene bienes"; una realidad transversal en la mayoría de las comunidades donde se instalaban escuelas (Ibíd.).

Acostumbrado a una rutina propia, el niño tomado por ejemplo en este caso, “en el verano, levantado mucho antes de salir el sol, sacude o deja botado los dos o tres pellejitos que le sirven de cama, sacude las cenizas que lo cubren y en que ha dormido, y tiene u[sted] a un hombre listo a principiar la tarea del día” (Ibíd.). Su tarea matutina: "sacar el lazo, suspendido cuidadosamente a algún garabato, y con un pedazo de cebo, ir sobándolo hasta que se ponga suave como seda [...] ese es el pasatiempo de todos los días hasta que tenga la edad de diez y ocho años” (Ibíd.).

El niño “es muy observador”, y a medida que crece, inferimos, crecen también sus habilidades cognitivo-biológico-sociales, asistiendo poco - o de plano nada - a la escuela. De este modo ha aprendido el lenguaje, que "es una mezcla de castellano y de mapuche [sic], ininteligible para los habitantes de los pueblos grandes. [Cabe destacar, no obstante, que] de una edad todavía muy tierna, es ya buen lenguaraz” (Ibíd.:22). En este sentido, y solo a modo de reflexión, cabe preguntarse ¿por qué habría pensado el niño en aceptar el llamado de asistir a la escuela para aprender lecto-escritura y desarrollar su vocabulario, si vivía "en una casa donde están todos revueltos, casados y solteros, hijos, hombres y mujeres, [y] las palabras más obscenas son recibidas como gracia y talento?...” (Ibíd.).

Transcurrido el tiempo, “ya tenemos a nuestro joven llegado a la edad de trece años. No tiene la menor idea ni deseo de saber lo que es lectura, escritura ni aritmética” (Ibíd.), porque fuera de la escuela es capaz de potenciar "todas sus facultades intelectuales y físicas” (Ibíd.). Y así, ajeno a la oferta de la educación popular, "se ha ejercitado en domar un potro, en arrastrar al pihuelo [sic] o bolear con el laque [sic] los animales de la montaña, en el gran arte para él de engañar y de no ser engañado, para no ser leso, como le han dicho mil veces sus padres” (Ibíd.). Cabe agregar que al desinterés académico se suma el no menos importante desinterés por los saberes religiosos, reflejado en una precaria formación cristiana del niño, que "se reduce a hacer de vez en cuando la señal de la Santa Cruz; [más es su creencia] en los brujos [sic], en los daños [sic], en los chonchones [sic], y en todas las absurdidades de los indígenas” (Ibíd.). 
Fuera de la escuela, además, el niño aprende a sociabilizar, a establecer los mal mirados lazos familiares y vecinales, a relacionarse con sus pares. Su cotidianeidad "la pasa a caballo visitando a los indios sus vecinos, para los cuales no deja de ser un buen parásito, o bien botado al sol" (Ibíd.). Aunque sólo es un niño, éste "piensa dónde habrá alguna tomadura [sic] de chicha o de muday [sic], para ir también a engrosar el número de los bebedores". Cabe aclarar, no obstante, que a pesar de beber con sus pares, lo hace "todavía con alguna cautela, porque [recordemos] no tiene más que trece años. ¡Qué lástima que sea de tan poca edad!!” (Ibíd.). Y así se la pasa, siempre sociabilizando, este niño "no pierde el tiempo enteramente; no olvida ejercita[r] con otros amigos en los diferentes juegos de naipes, que jamás faltan en su chaleco (cuando lo tiene)” (Ibíd.).

Acostumbrado a sus particulares lazos, "muy poco o ningún deseo tiene de visitar los pueblos; pero que se hable delante de él de una excursión a la tierra para ir a conchabar [confabularse para delinquir] o acompañar a algún comerciante; mi joven se pone radiante [...y] nada es capaz de detenerle” (Ibíd.). Creciendo de esta manera desarrolla costumbres incongruentes con las enseñadas en la escuela, fomentando "el poco respeto por la propiedad ajena, o para hablar sin disfraz y con mayor claridad, esa propensión al robo innata en él. [De tal manera que] a la edad a que ha llegado nuestro hombrecito, es un bípedo carnívoro, algo temible a los ganados de los vecinos” (Ibíd.:23). El niño desarrolla el pillaje con inteligencia, “con qué talento, con cuántas precauciones y de qué maulas no se vale para conseguir sus fines, y borrar hasta la menor señal del rastro que podría hacer sospechar al ojo observador del dueño de la presa, cual ha sido el autor del crimen [...]" (Ibíd.). Finalmente, creciendo "en esta funesta y perniciosa escuela [su propia experiencia], más tarde viene, a ser cuando grande, un temible ladrón más sanguinario y funesto para los animales del patrón, de quien es vaquero, que todos los leones de la cordillera” (Ibíd.).

Con el testimonio descrito anteriormente intentamos develar la situación de un niño popular, la prejuiciosa comprensión de su oposición a la escuela y de su construcción propia de la realidad. Ciertamente, no lo desconocemos, existían particularidades y heterogeneidades entre las distintas experiencias de los niños. Con todo, considerando las individualidades, el ejemplo narrado revela que los niños eran capaces de construir una realidad histórico-social propia, a veces distante de las normas sociales impuestas.

El caso expuesto, de algún modo, explica las interrupciones y resistencias a las doctrinas escolares ${ }^{15}$. El niño, lo veíamos, a base de pura experiencia, aprendió el robo, el pillaje, el vagabundaje tal vez, todas actividades rechazadas por el canon de la nueva nación ${ }^{16}$. Mas no generalicemos, no en todos los niños permeaban las mismas prácticas; con un $80 \%$ de los niños plebeyos "huachos" (Salazar y Pinto 2002:48) la heterogeneidad de los hábitos reinaba, pudiéndose encontrar incluso niños que "se embriaga[ba]n sin distinción casi todos los días de la semana, y comet[ía]n mil desórdenes y barbaridades” (“Ovalle”, MEP, Tomo V, nº12, septiembre 1857: 365). De 
todas formas -habiendo sectores donde la asistencia a la escuela correspondía a un 17avo de la totalidad en edad de educarse- sabido era que "los niños [eran] más aficionados a viciarse que a educarse; [y que huían] de las escuelas como huye el ladrón de la luz" ("Memoria que el visitador de las escuelas del departamento de San Fernando, pasa al señor Ministro de Instrucción Primaria”, MEP, Tomo VII, nº12, septiembre 1859: 274).

Aquella huida "de la luz" que los niños se rehusaban a seguir, sin embargo, no fue permanente; a veces los niños volvían al sendero edificado por las élites, sendero que poco a poco, y a base de inspección, cimentaba sus bases. De tal manera los niños asistían a las escuelas, aunque, valga la reiteración, lo hacían irregularmente. Quisiéramos por ello -habiendo visto ya las dificultades sociales, externas a las aulas- reflexionar en torno a las dificultades en las instancias académicas.

\title{
Las dificultades académicas
}

La escuela primaria popular, recordemos, debía adoctrinar a sus asistentes conforme a la nación homogénea en construcción, por lo tanto debía instruir bajo nuevos criterios morales, disciplinados, higiénicos, etc., incluso modificar el lenguaje, el vocabulario y la cultura oral imperante en los sectores populares. El niño popular debía en adelante alterar su esencia y llegar a ser un "hombre nuevo"17. En la escuela, afirmaban las autoridades:

\begin{abstract}
"Se pierden los malos instintos, se forma el ser moral del que va a ser hombre, el niño se ve sujeto a una autoridad y obediente a una regla de conducta, reconoce deberes que está obligado a cumplir [...] No hay niño, por desordenado que sean sus instintos, que no sufra una transformación saludable en los bancos de la escuela, mejorando su ser moral e intelectual(...) le da a conocer sus deberes para con Dios, la patria, sus padres y sí mismo, abriéndole al mismo tiempo las puertas del bienestar, enseñándole los medios de ganar la vida con honradez y de conquistar una posición social bien superior a la que tuvieron sus mayores”(MEP, Tomo III, n¹0, julio 1855: 292).
\end{abstract}

Con todo, antes que la escuela cambiase los hábitos de los niños populares, éstos llevaron los suyos a la escuela (Egaña y Monsalve 2005). De esta manera, por ejemplo, asistían "los alumnos con mantas en el rigor del sol, sin peinarse, cara, manos y pies desaseados, y uñas largas" ("Departamento de San Felipe”, MEP, Tomo II, $n^{\circ} 6$, enero 1854: 174). Hubo por tanto que alterar su identidad, modificar su apariencia, dejar atrás lo cotidiano, e incluso modificar la (su) cultura oral. Y es que además de la apariencia se debía corregir en "los niños los vicios de pronunciación que son tan comunes, de los que indicaremos los más esenciales a saber, la debilidad de las s finales en los plurales que los castellanos pronuncian silvándola fuertemente por requerirlo así la claridad. El cambio frecuente de la $\mathbf{r}$ por la $\mathbf{l}$, como sordao, er deo [sic]; la supresión de la d en la última sílaba de las palabras acabadas en ido, ida, como comia, querio [sic] ("Barbarismos", 
MEP, Tomo III, $n^{\circ} 3$, octubre 1854: 82). La escuela en este sentido debía consagrarse como "un salón de etiqueta, en que en lugar de decirse este habló, aquel llegó tarde, Juan me empujó o Antonio tomó mi libro, etc [sic]. [debían] considerarse unos a otros y desterrar el tú y el vos tan comunes al presente”. En consecuencia, se apremiaba a los niños para que suprimieran la sociabilidad aprendida en su cotidianeidad y cultivaran nuevas conductas; aprendiendo a conservar el orden en la clase, a mantener un asiento, a estudiar asiduamente sin conversar, a preocuparse solo de su estudio, de su lección (MEP, Tomo II, n¹2, julio 1854: 297). Con todo, pese al esmero de las autoridades por consolidar un método para la enseñanza/aprendizaje de la gramática castellana para que los niños adquirieran un nuevo lenguaje con nuevos códigos para la comunicación:

“Deteniéndose a observar el adelanto de los varios ramos [exponía un visitador], en lectura, salvo algunas escuelas fiscales, se lee mal y sin sentido; la lectura es viciada por la mala pronunciación de las letras y por la poca atención a las pausas. [...] La pronunciación la he visto corrompida en omitirse en general las consonantes últimas, en proferir las palabras entre dientes, no bien claras y comprensibles. El alfabeto español tiene la suerte de escribirse como se pronuncia; una buena pronunciación es parte esencial de la ortografía, y el alumno si no puede cursar gramática o no se le enseña podría a lo menos aprender y escribir su idioma con menos errores ortográficos. Se insistió [como fue la tónica] en corregir estos defectos" ("Memoria que el visitador de escuelas de la provincia de Chiloé pasa al señor Ministro de Instrucción Pública”, MEP, Tomo VI, nº , abril 1858: 197).

Del mismo modo que con la lecto-escritura, la enseñanza del sistema métrico decimal -ramo enseñado en la escuela- no era aprendido como se esperaba. Los niños aprendían las definiciones y “a retener en la memoria un corto número de nombres nuevos y algunas fórmulas” -hecho nada sorprendente para la habilidad de un niño-, “¿pero habrá comprendido el sistema [se preguntaban las autoridades]?” En concreto, no. El niño quedaba limitado a la repetición de teorías, pero no comprendía lo que repetía, ya que "el pobre niño que no puede formarse idea clara y precisa de lo que es una millonésima parte [...] que no sabe lo que es arco, ni cuadrante, ni meridiano, ni polo, ni ecuador, oye palabras que no entiende, y se queda en ayunas, como suele decirse, lleno de dudas y de confusión que lo desaniman inspirándole disgusto hacia el estudio" ("Sistema métrico decimal", MEP, Tomo VII, n², noviembre 1858: 40-41).

Además de no comprender lo enseñado, algunos niños dificultaban aún más el aprendizaje o la memorización de contenidos al no llevar sus materiales a la escuela. Es decir, sumado a la inasistencia, por ejemplo en un lugar donde hubo niños que faltaron a la escuela 232 días y otros solo asistiendo 50 veces, "se agrega otro [inconveniente] de no poca entidad, el cual consiste en que estos no llevan al establecimiento, con la debida regularidad, el papel, plumas y libros que necesitan para su aprendizaje. Con 
estos inconvenientes es imposible que un preceptor, por muy celoso que sea en el desempeño de sus deberes, pueda presentar progresos notables entre sus discípulos” (MEP, Tomo IV, $n^{\circ}$ 5, febrero 1856: 144). El hecho puede ejemplificarse también con una escuela de niñas, la escuela $\mathrm{N}^{0} 1$, donde el visitador de escuelas, entre asombro y congoja, exponía que: "increíble es la resistencia que estas alumnas ponen para aprender aritmética, y aun para algunas obras de mano, pues no traen al establecimiento, a pesar de requerimientos, elemento alguno para que se les enseñe algún tejido, o bordado, o costura” ("Informe que el visitador de escuelas de la provincia de Valdivia presenta al señor Ministro de Instrucción Pública”, MEP, Tomo VIII, n7, abril 1860: 201).

Las dificultades al modelo educacional-nacional no solo se manifestaron en las prácticas mencionadas, sino que además hubo otras más directas todavía. En este sentido, fácilmente se podía encontrar en los establecimientos educacionales "algunos muchachos díscolos e insolentes que no cedían a reprensiones ni castigos” ("Escuela municipal de Quilicura”, MEP, Tomo III, n², septiembre 1854: 51), e incluso algunos que en alguna oportunidad hayan "(con permiso del que esto lee), carajeado [insultando] en sus propias barbas [al preceptor]” (Ibíd.). Esta conducta fracturaba el orden jerárquico impuesto; en ello se manifiesta la infracción a las normas, la inconsideración por la autoridad y la obediencia. En consecuencia, se ordenó la expulsión inmediata del alumno, aconsejando además al preceptor a no permitir más dichos actos (Ibíd.).

Para prevenir hechos como el recién mencionado se sugería dirigir las aptitudes del niño popular buscando su interés por el aprendizaje, de lo contrario, “en medio de la confusión y bullicio, en vez de estudiar [el niño] rompe su libro, inquieta a su compañero, juega con los otros y promueve el desorden, [todo esto] a pesar del temor que inspiran el encierro, el azote, el gorro [sic] y otros instrumentos no menos indignos y vergonzosos que se ofrecen de continuo a su vista en ciertas escuelas" ("De la disciplina en las escuelas”, MEP, Tomo VII, n8, mayo 1859: 225). En otras palabras, el niño no le tenía miedo al castigo y optaba por anteponer su desorden cuando lo enseñado no era de su interés. Por su parte, ante tales actitudes el preceptor recurría a la amonestación, a la reprensión, a los gritos, y por último a los golpes "a diestro y siniestro a aquella turba que interrumpe por un momento sus travesuras para dar lugar al llanto y a las quejas. [No obstante], pasada la primera impresión de tan fuerte castigo, cediendo a una necesidad irresistible de su misma organización, los niños se agitan de nuevo, y se reproduce continuamente la desagradable escena [...]” (Ibíd.).

Tal como lo vemos, muchas veces esa fue la cotidianeidad en el aula; niños desordenandos, y preceptor castigando. Y así, entre desobediencias y reprensiones, los niños iban conociendo a su preceptor, hasta que, una vez conocidas sus debilidades, los niños:

“Se complacen en irritarlo, y le disputan y le niegan la consideración y respeto debidos al que ejerce las funciones paternales de desen- 
volver su inteligencia y formar su corazón, porque para ellos semejante preceptor no es sino un mercenario que llena a la fuerza los deberes de su ministerio, vengándose del trabajo que se imponen, maltratando a sus alumnos. De aquí la repugnancia al estudio; de aquí lo infructuoso de las lecciones; de aquí la pugna entre el que enseña y los que debieran aprender, origen fecundo y perenne de desazones y molestias para unos y otros. Es ruido ahora la voz del preceptor, la inquietud en medio de su interrumpida explicación lo cansa y fatiga y la resistencia y terquedad de los alumnos rebajan y ofenden su amor propio; de suerte que la escuela viene a ser para él un verdadero tormento y espera con ansia la hora de terminar los ejercicios[...]”(Ibíd.:226).

El caos que refiere esta última cita grafica fielmente las dificultades del proceso en cuestión; las múltiples manifestaciones de los niños frente al modelo que se deseaba construir; la desobediencia, el desorden, la animadversión con el estudio, la desconsideración ante la autoridad, en fin, las barreras que los niños imponían al desarrollo de un modelo infructuoso para sus necesidades.

\section{Conclusiones/Consideraciones finales}

En el contexto histórico que la educación popular dio sus primeros pasos, proliferaron también al alero del Estado diversas instituciones educacionales, piénsese en la Universidad de Chile, la Escuela Normal de Preceptores y la Escuela de Artes y Oficios. En los representantes de la República Conservadora en Chile apremiaba la necesidad de ordenar al país en función de la inserción de éste en la modernización occidental, pues sólo manteniendo un orden interno Chile podría integrarse a los cánones importados de los países considerados como referentes ideales. En este sentido, los sistemas de enseñanza se tornaron un instrumento para lograr aquel objetivo, para ordenar la sociedad y formar/reproducir élites y sectores populares; de ahí el diseño de sistemas de enseñanza clasistas.

El Estado impulsó desde comienzos de la década de 1840 una mayor inversión monetaria para el desarrollo de sistemas de enseñanza, sin embargo no fue suficiente para cumplir el objetivo propuesto ${ }^{18}$. No reducimos con esta afirmación el problema sólo a un aspecto económico, pues el problema responde a la estridente pugna que supone homogeneizar la cultura en un Estado-nación en construcción.

En síntesis, entre 1840 y 1860 el proyecto educacional-nacional impuesto por las élites supuso distintas dificultades, entre ellas -decía un visitador de escuelas-, "la poca difusión de libros por su suma escasez en la carencia de útiles, la falta de uniformidad en el método [de enseñanza], el número de materias de enseñanza, la inasistencia de los alumnos, la poca cooperación de los padres, el no ser obligatoria la instrucción, la falta de preceptores más idóneos, la poca dedicación de los mismos, la escasa retri- 
bución de sus servicios, la pobreza de las familias" (Memoria que el visitador de escuelas de la provincia de Chiloé pasa al señor Ministro de Instrucción Pública” MEP, Tomo IV, n7, abril 58: 198). Las dificultades administrativas obedecieron a un Estado precariamente organizado; las dificultades sociales, por su parte, respondieron a la manifestación de una realidad incongruente con las bases de los ideales que el Estado pretendía consolidar en el nuevo modelo de nación. "Desde arriba” se acusó a los niños populares y su familia de ser ignorantes, porque "la ignorancia desconoce su interés cuando no palpa y percibe la ventaja cercana e inmediatamente" (“Ley Orgánica de Instrucción Primaria”, MEP, Tomo VIII, n¹0, julio 1860: 291); de ahí la molestia de las autoridades y el desprecio hacia los niños populares, por no asumir un tipo de saber, innecesario para su cotidianeidad. Por el contrario, antes que aprender saberes académicos, no era extraño ver "escuelas bien servidas sin alumnos en medio de poblaciones numerosas, al paso que los niños vaga[ba]n por las calles sin preocupación, u ocupados en adquirir vicios” (Ibíd.).

Las dificultades analizadas en este artículo ocurrieron mientras los visitadores de escuela cumplían dos roles: conciliador y administrativo. Con la creación de la Ley Orgánica de Instrucción Primaria en 1860 el escenario cambiaría; el rol conciliador o social de los visitadores quedaría en adelante obsoleto, conservando exclusivamente su carácter administrativo. Con la nueva Ley, además, se crearía un nuevo cargo: el de Inspector General, de quien dependerían los visitadores de escuela. De este modo, la jerarquía burocrática-estatal quedaría precedida por el Ministro de Instrucción Pública, seguido por el Inspector General y luego por los visitadores de escuela (Ley General de Instrucción Primaria, 24 Noviembre 1860).

Dicho esto, observamos que cuando no se logra un consenso entre el Estado y los sectores populares, aumentar la inspección pareciera ser la alternativa. Cuando la construcción propia de la realidad de los sectores populares es incompatible con los proyectos estatales, no queda más que opacarla, enterrarla. Emulando la realidad europea y estadounidense se intentó cambiar la cotidianeidad de los niños populares, alterando su identidad e integrándolos a un modelo infructuoso e improductivo para ellos. Ofreciendo al niño popular una educación elemental, se intentó quebrar su habitualidad, su diario vivir, intentando transformarlo en un "hombre nuevo" acorde a las necesidades del nuevo modelo en construcción. 


\title{
Notas
}

${ }^{1}$ Programa de Magíster en Historia, Universidad de Chile, Santiago de Chile. Emilioramirez@live.

${ }^{2}$ El presente artículo expone parte de la investigación realizada para optar al grado de Licenciado en Historia.

\begin{abstract}
${ }^{3}$ No es casual que en esta década se haya dado inicio al proyecto de educación popular, sino que habría sido consecuencia del orden de las arcas fiscales, una mayor disponibilidad de recursos a causa del auge minero en el norte del país, y el cese de las pugnas intra-elite (Serrano 1998:343) (Mac-Clure 2012: Cap. III). Cabe mencionar en este sentido que antes de la década de 1840 hubo escuelas en la Patria Vieja, bajo el sistema lancasteriano (proyecto impulsado por O’Higgins) y existían escuelas conventuales. Sin embargo, ninguna de éstas poseía las características de las impulsadas en el período en cuestión (Monsalve 1998: 17)
\end{abstract}

${ }^{4}$ Un análisis sobre la relación entre el trabajo de los niños, el hogar y la escuela puede verse en Serrano; Ponce de León; Rengifo (2012: Cap. V).

${ }^{5}$ Sarmiento hacía esta afirmación porque en la escuela se distribuía el tiempo, habían varios alumnos, materiales y maestros; todo esto dentro de un local, con un método a seguir, economizando el tiempo y dando vastos resultados (Sarmiento 1849: 187)

${ }^{6}$ La metáfora de los “sordo mudos de la civilización” alude, en palabras de los mismos autores, a "la escritura como lengua que sirve para transmitir de generación a generación la sabiduría de los siglos. [Y a] la lectura [como] el oído que tienen los hombres para escuchar las advertencias y los consejos de los que les han precedido en la vida. El que no sabe escribir está mudo para dar a conocer sus pensamientos a la posteridad; el que no sabe leer está sordo para recibir las lecciones de la experiencia” (Ibíd: 13).

${ }^{7}$ La sigla MMJCIP significa Memorias del Ministro de Justicia, Culto e Instrucción Pública.

${ }^{8}$ La fuente fue extraída de Pinto y Valdivia (2009:246).

${ }^{9}$ La Historia de la Educación (primaria) y la Historia Social de la Educación (primaria) en Chile han centrado sus esfuerzos en estudiar la institucionalidad educacional, los actores sociales que la componen y el proceso de escolarización. Por nombrar algunos ejemplos: (Labarca 1939); (Harriet 1960); (Soto 2000); (Egaña 2000); (Serrano 1999); (Ponce de León 2010); (Rengifo 2012). Para más detalles sobre el desarrollo de la historiografía relativa a la educación en Chile ver Pablo Toro (2011). Por otra parte, estudios relacionados a la historia de la infancia en Chile han aportado en sobremanera a la comprensión de la realidad de los niños, en diversos períodos de la historia de Chile. Entre otros: (Salazar 2006); (Illanes 1991); (Rojas 2010). Con todo, no se han analizado las prácticas y actitudes de los niños populares desde sus propias concepciones, develando su propia conciencia y capacidad de decidir por la asistencia o abstinencia a la escuela primaria.

${ }^{10}$ La Sigla MEP significa El Monitor de Escuelas Primarias. 
${ }^{11}$ El cargo de visitador correspondía a "un plan de ascensos para los preceptores primarios” (Sanfuentes, MMJCIP, 1847: 27).

${ }^{12}$ Como promedio se educaba a un niño por cada 9, 35. Las cifras de los educados en las trece provincias de la época eran las siguientes: en Chiloé, 1 por cada 3,59; en Atacama,1 por 5,00; en Valparaíso, 1 por 6,38; en Valdivia, 1 por 6,78; en Santiago,1 por 8,83; en Coquimbo, 1 por 9,00; en Concepción,1 por 10,00; en Aconcagua, 1 por 11,00; en Arauco, 1 por 11,20; en Talca, 1 por 11,32; en Colchagua, 1 por 14,85; en Maule, 1 por 15,00; en Ñuble, 1 por 20,00 (Silva, MMJCIP, 1857: 17).

${ }^{13}$ Quien propone este ejercicio, es decir, quien propone leer de las fuentes oficiales "en reverso" o a "contrapelo" para develar la conciencia de los sectores subalternos es Rinajit Guha. Para profundizar en ello véase Guha (1999).

${ }^{14}$ Comprendemos que la alusión al niño como “de la frontera” en esta fuente responde a un niño mestizo; desprendemos este dato por la lectura de la fuente y porque parte de la población que habitaba La Araucanía era mestiza (León 2005). Para el caso de un niño indígena propiamente tal puede examinarse el caso de las escuelas misionales. Allí se quejaban las autoridades diciendo: “es inaudita la resistencia que ponen los niños indígenas al aprendizaje; continuamente huyen de la misión, y es preciso que el capitán de amigos vaya de casa en casa buscándolos y amenazando a sus padres para que los entreguen y vuelvan a las escuelas.” Se quejaban además porque los niños se ocultaban en los cerros, fugitivamente, para huir de la persecución de las autoridades, y que, además "los pequeños desde la edad de ocho años son tan beodos [borrachos] como los de treinta, quienes desde muy temprano emprenden la faena de instruir a los rapaces en la crápula [borrachera]" ("Memoria que el visitador de escuelas de la provincia de Valdivia pasa al señor Ministro de Instrucción pública de la visita practicada en el departamento de la Unión”, MEP, Tomo VI, n 8, mayo 1858: 244).

${ }^{15}$ A modo de dato solamente, y para enfatizar que el caso del "niño de la frontera" no era un caso aislado, cabe señalar que en la zona en cuestión, de 7.500 niños aproximadamente en edad de educarse solo 287 hombres y 126 mujeres recibían instrucción estatal ("Informe del visitador de escuelas de Los Ángeles [visitando la provincia de Arauco] don Manuel Valenzuela”, MEP, Tomo III, n9 , junio 1855: 271).

${ }^{16}$ La educación primaria popular, en función de la modernización del país, debía adoctrinar a los sectores populares bajo los cánones de la civilización, moralizando, de este modo Chile podría integrarse a los circuitos comerciales internacionales (Egaña 2000:13). Cabe agregar que en Chile después de 1829 se impuso un régimen político de élites mercantiles, desplazando al sector pipiolo-productivo. Bajo esta lógica, urgió moralizar y civilizar las costumbres populares para eliminar el contrabando, el bandolerismo y, en fin, las costumbres populares que interrumpían la regulación del sistema económico-político impuesto (Salazar, 1987: 89).

${ }^{17}$ La historiografía relativa a la historia de la educación en Chile ha consensuado en que desde el Estado se impulsó la creación de un "hombre nuevo" homogeneizando la cultura, aunque no se ha consensuado en la finalidad de la creación de éste. Por una parte, ver los argumentos de Serrano (1999), (Serrano 1990), (Serrano 1994), (Iglesias 2009); por otra parte, ver los argumentos de Monsalve (1998) (Egaña 2000) (Egaña y Monsalve 2005), (Egaña 1994). 
Polis, Revista Latinoamericana, Volumen 13, $N^{\circ}$ 37, 2014

${ }^{18}$ A modo de dato, cabe señalar que el presupuesto invertido en Educación Pública resultó insignificante en comparación con la inversión en materia de guerra. En materia educacional el Presupuesto Fiscal osciló entre un 1 y 4\% en el período 1842-1850, mientras que para el ministerio de Guerra y Marina la cifra osciló entre 33,3 y 40,3\%. La variación de la situación es ínfima en el desarrollo de los años que siguieron; entre 1850 y 1900, del presupuesto fiscal total, como promedio se invirtió solo un 5,4\% en educación, mientras que en Guerra y Marina el promedio fue de 30,1\% (Salazar 1987: 91). 


\section{Bibliografía}

\section{Fuentes primarias}

Amunátegui, Miguel y Gregorio (1856), De la instrucción primaria popular en Chile: lo que es, lo que debiera ser, Imprenta del Ferrocarril, Santiago de Chile.

Boletín de las Leyes y Decretos del Gobierno (1 de marzo de 1854), Libro XXII N³.

El Monitor de Escuelas Primarias (MEP) (1852-1860) 12 vols., Imprenta de Julio Belin, Santiago de Chile.

Ley General de Instrucción Primaria (24 de noviembre de 1860), Santiago de Chile.

Memoria del Ministerio de Justicia, Culto e Instrucción Pública (MMJCIP) (1840-1860).

Sarmiento, Domingo F (1849), De la educación popular, Imprenta de Julio Belin y Compañía, Santiago de Chile.

\section{Fuentes secundarias}

Campos Harriet, Fernando (1960), Desarrollo educacional. 1810-1960, Editorial Andrés Bello, Santiago de Chile.

Delval, Juan (1989), “La representación infantil del mundo social”. En El mundo social en la mente infantil. Turiel, Elliot; Enesco, Ileana; Linaza, Josetxu (Eds.), Alianza Editorial, Madrid, 245-327.

Egaña, Loreto (2000), La educación primaria popular en Chile en el siglo XIX: Una práctica de política estatal, DIBAM, PIIE, LOM Ediciones, Centro de Investigaciones Diego Barros Arana, Santiago de Chile.

Ibídem (1994), "Pedagogía y modernidad. Configuración del sistema de educación primaria popular en el siglo XIX en Chile”. En Proposiciones, $\mathrm{N}^{\circ}$ 24.

Egaña, Loreto y Monsalve, Mario (2005), “Civilizar y moralizar en la escuela primaria popular”. En Historia de la vida privada en Chile. Tomo II. Sagredo, Rafael y Gazmuri, Cristián (Eds.), Taurus, Santiago de Chile, 119-137.

Guha, Rinajit (1999), “La prosa de la contrainsurgencia”. En Dube, Saurabh (coordinador), Pasados Poscoloniales, El Colegio de México, México.

Iglesias, Ricardo (2009), “El papel de la educación en la construcción del 
Estado nacional chileno en el siglo XIX”. En Cid, Gabriel y San Francisco, Alejandro (Eds.). Nación y Nacionalismo en Chile. Siglo XIX, Centro de Estudios Bicentenario, Santiago de Chile.

Illanes, María Angélica (1991), Ausente, señorita. El niño chileno, la escuela para pobres y el auxilio, 1890-1990, JUNAEB, Santiago de Chile.

Labarca, Amanda (1939), Historia de la enseñanza en Chile, Ediciones de la Universidad de Chile, Santiago de Chile.

León, Leonardo (2005), Araucanía: la violencia mestiza y el mito de la pacificación, 1880-1900, Universidad Arcis, Santiago de Chile.

Mac-Clure, Oscar (2012), En los orígenes de las políticas sociales en Chile 1850-1879, Ediciones Universidad Alberto Hurtado, Santiago de Chile.

Monsalve, Mario (1998), “...I el silencio comenzó a reinar”. Documentos para la Historia de la Instrucción Primaria. 1840-1920, DIBAM, Santiago de Chile.

Pinto, Julio y Valdivia, Verónica (2009), ¿Chilenos todos? La construcción social de la nación (1810-1840), LOM Ediciones, Santiago de Chile.

Ponce de León, Macarena (2010), “La llegada de la escuela y la llegada a la escuela. La extensión de la educación primaria en Chile, 1840-1907”. En Historia. Pontificia Universidad Católica de Chile. Vol. II, $N^{\circ} 43$, Santiago de Chile, 449-486.

Ranciére, Jacques (2010), La noche de los proletarios: archivos del sueño obrero, Tinta Limón Ediciones, Buenos Aires.

Rengifo, Francisca (2012), “Familia y Escuela. Una historia social del proceso de escolarización nacional”. En Historia. Pontificia Universidad Católica de Chile. Vol. 1, N 45, Santiago de Chile, 123-170.

Rojas, Jorge (2010), Historia de la infancia en el Chile republicano, 18102010. JUNJI, Santiago de Chile.

Ruiz, Carlos (2010), De la República al mercado, LOM Ediciones, Santiago de Chile.

Salazar, Gabriel (1987), “Los dilemas históricos de la auto-educación popular en Chile ¿integración o autonomía relativa?”. En Proposiciones, №15, 83-129.

Ídem (2006), Ser niño “huacho” en la historia de Chile (siglo XIX), LOM Ediciones, Santiago de Chile.

Salazar, Gabriel y Pinto, Julio (2002), Historia Contemporánea de Chile. 
Niñez y Juventud. Tomo V, LOM Ediciones, Santiago de Chile.

Serrano, Sol (1998), “La escuela chilena y la definición de lo público”. En Los espacios públicos en Iberoamérica. Ambigüedades y problemas. Siglos XVII-XIX. Guerra, François-Xavier; Lempéroère et al (Eds.), Fondo de Cultura Económica, México, 340-362.

Ídem (1990). “La Revolución Francesa y la formación del sistema nacional de educación en Chile”. En Krebs, Ricardo y Gazmuri, Cristián, La Revolución Francesa y Chile, Editorial Universitaria, Santiago de Chile.

Ídem (1999). “¿Quién quiere la educación?, Estado y familia en Chile a mediados del siglo XIX”. En Educación y familia en Iberoamérica. Gonzalbo, Pilar (Editora), Colegio de México, México.

Ídem (1994), Universidad y Nación. Chile en el siglo XIX, Editorial Universitaria, Santiago de Chile.

Serrano, Sol; Ponce de León, Macarena; Rengifo, Francisca (2012), Historia de la Educación en Chile (1810-2010). Tomo I. Aprender a leer y escribir (1810-1880), Taurus, Santiago de Chile.

Soto, Freddy (2000), Historia de la educación chilena, CPEIP, Santiago de Chile.

Toro, Pablo (2011), "Momentos y tendencias en el desarrollo de la historiografía de la educación en Chile (1850-2010). En Cadernos de História da Educação, № 2, Vol 10.

Recibido: 16.02.2014

Aceptado: 31.03.2014 